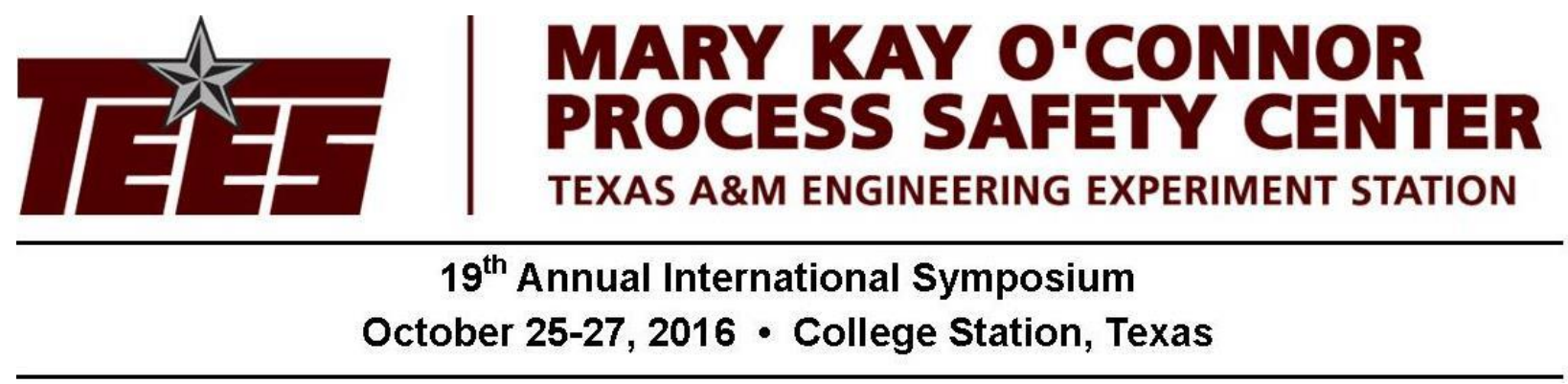

\title{
Benefits of Simple Consequence Modeling for Burner Management Systems
}

\author{
Matthias Braedel \\ aeSolutions \\ 3800 Centerpoint Drive, Suite 620 \\ Anchorage, AK 99503 \\ matthias.braedel@aesolns.com
}

Keywords: Process Hazard Analysis (PHA), Safety Integrity Level (SIL), Safety Instrumented System (SIS), Process Safety Information (PSI), Hazard and Operability (HAZOP) Study

\begin{abstract}
The current approach used to analyze fired heaters during a Process Hazard Analysis (PHA) is inefficient and outdated. Fired heaters can be one of the more complex systems evaluated in a PHA, however they certainly aren't anything new. In fact, they are one of the most common pieces of process equipment throughout industry, and have been for quite some time. Why then is such a large amount of PHA team time still needed to analyze them? Why, when using the same Process Safety Information (PSI), methodology, and risk criteria, can the results still be inconsistent? The obvious answer is the PHA team; different teams yield different results. Since the results of a PHA can impact several facets of a facility and its operation, including driving the Safety Integrity Level (SIL) for the heater's Burner Management System (BMS), inconsistencies between analyses can have significant safety and financial impacts. If the consequence estimation is over conservative the selected SIL may be too high, which will result in an over designed and a very costly Safety Instrumented System (SIS). Conversely, if the consequence estimation is too low, the facility's risks may not be adequately reduced by the selected SIS. Therefore a means to efficiently and consistently determine the consequence is critical. This paper will describe how simple consequence modeling can solve this problem, its inherent benefits, and the cost savings it provides.
\end{abstract}

\section{Introduction}

A PHA is an organized and systematic assessment of a process in order to ensure potential process hazards are identified, evaluated, and controlled. PHAs are less formally known as a hazard analyses or hazard review in the process safety industry and they are typically performed 
to comply with process safety requirements set by the Occupational Safety \& Health Administration's (OSHA) Process Safety Management (PSM) and Environmental Protection Agency's (EPA) Risk Management Plan (RMP) regulations established in the 1990s. Formal hazard analyses however are not anything new, they have been a part of the chemical process industry for more than 30 years. The most well-known and commonly used methodology, Hazard and Operability (HAZOP) Study, has even been used since the 1960s [1].

The tools available to perform a PHA have improved significantly over the past two decades, methodologies have been refined, and software programs provide a more fluid analyses and overall view of process risk. Despite these improvements, one problem still commonly encountered in PHAs is the level to which consequence impacts are evaluated and documented. For instance, when evaluating the impacts of a vessel overpressure scenario, the consequence is often documented as "potential overpressure and rupture, resulting in a loss of containment and severe injury/fatality to nearby personnel". Though this level of consequence evaluation and documentation is not technically incorrect, it makes severity determination difficult when a risk matrix has different severity rankings depending on the number of potential fatalities.

In general, an accurate determination of a scenario's health and safety impacts is important, but it should be considered critical when evaluating process equipment with the potential for high severity impacts over large areas. Equipment located in confined spaces which are supplied with flammable substances have this potential, and one of the most common examples of this is fired heaters. Thus, when evaluating fired heaters in a PHA, strong consideration should be made to using consequence modeling to quantify the potential impacts of heater explosion scenarios so that accurate consequence estimations can be made and the severity confidently selected.

\section{Consequence Estimation and Risk}

Consequence estimation is vital to evaluating the risk of a hazard scenario. In CCPS Guidelines for Developing Quantitative Safety Risk Criteria [2], the definition of consequence is provided as follows:

\footnotetext{
"The undesirable result of an incident, usually measured in health and safety effects, environmental impacts, loss of property, and business interruption costs.”
}

While this definition does provide a starting point for estimating the consequence of an event, differences in personal experience and interpretation can result in significantly different severity/consequence estimations. This is especially true when team members change partway through a PHA, or between different PHA studies. By providing a way for teams with varying experience and interpretation to align their opinions when evaluating the consequences of a heater explosion, the inconsistencies in their consequence estimation can be corrected.

The definition of risk provided in the Guidelines for Developing Quantitative Safety Risk Criteria [2] is: 
"A measure of human injury, environmental damage, or economic loss in terms of both the incident likelihood and the magnitude of the loss or injury. A simplified version of this relationship expresses risk as the product of the likelihood and the consequences (i.e., Risk = Likelihood $x$ Consequence) of an incident."

The simplification of risk this definition provides shows that likelihood and consequence are the two variables required to determine risk. If one of the two variables is inaccurate, or not correct, then so is the solution (i.e. risk). Industry failure rate data is abundant and justifiable for use when process specific data isn't available. PHAs using semi-quantitative or fully quantitative methods can use this industry data for likelihood determinations and yield defensible results. For consequence determination however, there is not the same abundance of data available.

For most scenarios, the consequence can be determined within a relative degree of certainty using available PSI, basic arithmetic, and the team's knowledge and experience. For example, the consequence of overfilling a vessel containing nitric acid can be easily calculated (available volume/ fill rate $=$ time until overfill, time exceeding available volume $\mathrm{x}$ fill rate $=$ quantity released). Depending on the availability of secondary containment, the area of impact is either limited to the diked area or how far the material would spread if at a depth of 1 centimeter. Using this information with a facility plot plan can give a good estimate of the area of impact in order to confidently select the severity of the consequence. Performing consequence modeling on a scenario such as this, or those resulting in localized impacts, would not provide much added benefit.

The benefits of consequence modeling are most notable when evaluating scenarios with a potential for high severity impacts over large areas. Fired heaters have this potential and they are not unique to one particular industry. The concern here is not the majority of scenarios, it is the minority; the handful of identified hazard scenarios that can result in major safety or environmental impacts, that have the potential to change the way a facility operates, that can lead to national attention, or end up as the topic of a Center for Chemical Process Safety (CCPS) Process Safety Beacon. Without performing overpressure estimate calculations or consequence modeling, there is no justifiable way for a team to determine if a heater explosion could impact a normally occupied area (e.g. offices, control rooms, and sleeping quarters), and if it did, to what extent. After all, how can the risk of a hazard scenario be considered accurate if the consequence isn't?

\section{Consequence Modeling}

Consequence modeling is a tool that can be used to estimate the physical impacts of a process upset resulting in an explosion, fire, or toxic release with respect to their potential impact on people and the surrounding area. There are many software programs available that can perform consequence modeling. They have the ability to recreate equipment configurations and process conditions to evaluate specific hazard concerns in great detail. Consequence modeling such as this can be used to evaluate heater explosion scenarios identified in a hazard analysis, but, due to its specific nature, is very time consuming. 
In order to model a heater explosion, at a minimum, the following equipment specific information has to be determined:

1) Fuel type (e.g. natural gas)

2) Fuel feed pressure

3) Fuel feed temperature

4) Heating capacity (MMBTU/hr) or fuel feed rate (lbs./hr, lbs./min, or $\mathrm{ft}^{\wedge} 3 / \mathrm{min}$ )

5) Firebox volume $\left(\mathrm{ft}^{\wedge} 3\right)$

6) Combustion air supply $\left(\mathrm{ft}^{\wedge} 3 / \mathrm{min}\right)$

Most of the above listed information should be readily available during a PHA and therefore easy to determine. Information such as combustion air supply and firebox volume is not always available, but can be determined with the use of fan curves and design drawings.

A heater explosion requires both a sufficient flammable mixture and sufficient energy for ignition within the firebox. The ignition requirements for an explosive charge are very small, making it almost impossible to protect against all possible sources of ignition, such as static electricity discharges and hot surfaces. Therefore, unless design information or calculations such as those provided in NFPA $86 \S A$.8.5.1.8(3) say otherwise, when evaluating scenarios resulting in a loss of flame (i.e. combustion) it is appropriate to evaluate the consequence conservatively and assume an explosive accumulation will form and ignite. Some of the common causes of loss of flame leading to the formation of an explosive accumulation, regardless of operating mode, include:

- Pressure control malfunction above stable burner limits

- Pressure control malfunction below stable burner limits

- Combustion air supply malfunction

Other initiating causes such as flow control malfunctions can also result in a loss of flame. However, causes such as this vary depending on a heater's configuration, and should be evaluated on a case-by-case basis.

Performing consequence modeling during a PHA to determine the impact area of a heater explosion is not an efficient use of the team's time; therefore, the current approach generally results in making recommendations requiring a more detailed analysis to be performed outside of the meeting in order to confirm the team's initial estimates. The problem with this approach is that PHA recommendations are often not addressed until months (sometimes even years) after the PHA has concluded. If a team's initial consequence impact estimates were too low, a facility's risks may not be adequately reduced by the installed protection layers and may be operating beyond its risk threshold, posing an increased danger to personnel and providing a false sense of security. Another problem is if the recommendation was addressed and the modeling results showed that the team's initial estimates were incorrect, a team may have to be reconvened in order to update the scenario. Reconvening a team in order to update a scenario can be difficult due to scheduling conflicts and become expensive. 
Consequence modeling should extend beyond just evaluating specific scenarios coming out of a PHA. It should be used proactively, before a PHA, to evaluate the most common causes of loss of flame. The goal is, the next time a "loss of flame resulting in an explosive accumulation, ignition, and explosion" scenario is evaluated in a PHA, the question of "how bad can it get?" can be easily answered. This can be achieved as follows:

- Consequence modeling inputs have to be simplified to cover a range of different heater configurations. This includes but is not limited to: fuel types, firebox sizes, and heating capacities.

- Modeling inputs should consider the most common causes of a loss of flame such as combustion air and pressure control malfunctions. Causes unique to the heaters being evaluated or those identified in previous PHAs should also be considered.

- Modeling results have to be simplified so they are easy to use by a PHA team. Refer to Section 5 for details.

An example is provided in Section 4.1 of a chemical process involving multiple fired heaters. The intent of this example is to show how available process and equipment information for heaters having different sizes (firebox volume) and heating capacities can be simplified and used to evaluate some of the most common causes leading to a loss of flame (e.g. pressure regulator malfunction, combustion air malfunction, etc.). When simplifying this information it is important to remain conservative so that the modeling results are also justifiable for the more hazardous heater configuration (e.g. larger heater).

\section{Simple Consequence Modeling}

The CCPS Guidelines for Consequence Analysis of Chemical Releases [3] states that all models, including consequence models, have uncertainties, and they arise due to incomplete understanding of the geometry of a release, poorly characterized physical properties, and unknown or poorly understood mixture behavior, to name a few. Uncertainties that arise when performing consequence modeling are addressed by using conservatively simplified process and equipment information for modeling inputs. Simple consequence modeling is therefore conservative by design in order to remain justifiable for use in the event of uncertainties such as fuel supply pressure or temperature changes.

\subsection{Example Scenario}

XYZ Chemical Company operates a facility with eight natural gas (88\% Methane, 12\% Ethane) fired heaters at different stages of their process in order to maintain temperatures within a desired range. The heaters have varying firebox volumes with the smallest being $48 \mathrm{ft}^{\wedge} 3$ and the largest being $\sim 1000 \mathrm{ft}^{\wedge} 3$. The design heating capacity for each heater also varies between 1.3 MMBTU/hr and $30 \mathrm{MMBTU} / \mathrm{hr}$. Fuel gas is supplied to each heater from a main header at 200 psig, which is then reduced to 150 psig via a pressure regulator. The pressure is then reduced again at the heaters to 15 psig supply pressure. Fuel gas supply temperatures are controlled to at least $60{ }^{\circ} \mathrm{F}$, but can be as high as $80^{\circ} \mathrm{F}$ in the summer. The combustion air supply for the heaters was unknown. 


\subsection{Steps for Creating the Models}

The below steps show how to simplify the information provided in the example for each required modeling input. The steps are the same whether evaluating one facility or multiple facilities.

Step 1: Determine fuel type

- $\quad$ Actual: Natural gas (88\% Methane, $12 \%$ Ethane)

- Use: $100 \%$ Methane for the modeling

Methane provides for slightly more conservative results than if the natural gas at the provided composition was used because the heat of combustion for methane is greater. Also, since natural gas generally consist of 80-95\% methane, using it for the modeling will allow the results to apply to a greater range of fuel fired heaters.

Step 2: Determine heating capacity

The consequence models should cover the range of fired heater capacities that will be evaluated. For this example, the lowest heating capacity was $1.3 \mathrm{MMBTU} / \mathrm{hr}$, and the highest 30 MMBTU/hr. The number of capacities selected for the modeling and their range should be such that the heaters being evaluated will be close to one selected, if not exact.

- Actual: 1.3 MMBTU/hr is the lowest and $30 \mathrm{MMBTU} / \mathrm{hr}$ is the highest

- Use: A range between what is provided. For example: $1.5 \mathrm{MMBTU} / \mathrm{hr}, 3 \mathrm{MMBTU} / \mathrm{hr}, 6$ MMBTU/hr, $12 \mathrm{MMBTU} / \mathrm{hr}, 18 \mathrm{MMBTU} / \mathrm{hr}, 24 \mathrm{MMBTU} / \mathrm{hr}$, and $30 \mathrm{MMBTU} / \mathrm{hr}$

Heating capacities can also be used to calculate feed rates as follows:

- $\quad$ 1.5 MMBTU/hr for example, :

$$
\frac{1,500,000 \mathrm{BTU} / \mathrm{hr}}{\text { Fuel Heating Value }\left(\frac{B T U}{l b s}\right)}=X \frac{l b s}{h r}=>\frac{X l b s / h r}{60 \mathrm{mins}}=Y \mathrm{lbs} / \mathrm{min}
$$

Step 3: Determine heater firebox volume

As with heating capacity, the consequence models should cover the range of fired heater volumes that will be evaluated. For this example, the smallest heater had a firebox volume of 48 $\mathrm{ft}^{\wedge} 3$, and the biggest $1000 \mathrm{ft}^{\wedge} 3$. The number of volumes selected for the modeling and their range should be such that the heaters being evaluated will be close to one selected, if not exact.

- Actual: $48 \mathrm{ft}^{\wedge} 3$ is the smallest and $1000 \mathrm{ft}^{\wedge} 3$ is the biggest

- Use: A range between what is provided. For example: $50 \mathrm{ft}^{\wedge} 3,100 \mathrm{ft}^{\wedge} 3,150 \mathrm{ft}^{\wedge} 3,300$ $\mathrm{ft}^{\wedge} 3,500 \mathrm{ft}^{\wedge} 3,750 \mathrm{ft}^{\wedge} 3$, and $1000 \mathrm{ft}^{\wedge} 3$

Step 4: Determine combustion air supply (can be calculated using feed rate and fuel type) 
- Actual: Unknown

- Use: Stoichiometric ratio for air-fuel. This can be calculated using the feed rate and fuel type (e.g. $17.2: 1$ by mass for methane)

- Combustion air malfunction: $1.15 x$ stoichiometric concentration

When combustion air supply rates/design ratios are unknown, the stoichiometric fuel-air ratio should be used to calculate the combustion air supply. If excess combustion air (e.g. 15\% > stoichiometric) is standard for all heaters being evaluated, it should be considered. For combustion air malfunction, the severity of a confined fuel-air explosion peaks close to, but somewhere above, the stoichiometric concentration. In practice, $1.15 \mathrm{x}$ the stoichiometric concentration provides worst-case results, and therefore provides conservative overpressure estimates.

Step 5: Determine feed pressure

- Actual: 150 psig and 15 psig

- Use: 15 psig as normal

- Regulator malfunction: $150 \mathrm{psig}$ for regulator malfunction high, regulator malfunction low should be based on low pressure stability limits if available (5 psig can be used if not available)

Feed pressures should be determined using process specific setpoints and equipment design information (i.e. flame stability limits) when available. The modeling results will be impacted by a change in feed pressure, however, the impact is considered negligible as long as other modeling inputs remain conservative.

Step 6: Determine feed temperature

- Actual: $60^{\circ} \mathrm{F}$ to $80^{\circ} \mathrm{F}$

- Use: $70^{\circ} \mathrm{F}$ (the average)

As with feed pressure, feed temperatures should be determined using process specific information. In a range, the average is generally considered a good input value. The modeling results will be impacted by a change in feed temperature, however, the impact is considered negligible as long as other modeling inputs remain conservative.

Step 7: Determine heater location from grade

- Actual: Not provided

- Use: Located at grade

Unless all heaters being evaluated can be confirmed as being elevated above grade, the equipment locations should be conservatively assumed as being located at grade (i.e. on the ground). By doing this the calculated explosion energy will increase to account for the effects of 
reflection on the overpressures. If heater locations at a facility vary between being elevated and at grade, the modeling should be simplified such that all are at grade.

Step 8: Determine the release duration

The release duration should be long enough to reach steady state. For gas fired heaters, it is recommended that the release duration be selected using EPA RMP \$68.25(e)(1) for the worstcase release scenario for flammable gases (i.e. 10 minutes). In practice, a 10 minute release duration has been long enough to reach steady state.

Step 9: Determine overpressure levels of concern

For explosion analysis, determination of what overpressure levels are of concern to a facility is a critical step for all consequence modeling. There are many factors to be considered for making that determination. For evaluating the impacts of a heater explosion in a PHA, the most common factor in determining overpressure levels of concern is generally personnel and building type. Specifically, for normally occupied buildings located near fired heaters. Lees' Loss Prevention in the Process Industries: Hazard Identification, Assessment and Control [4] provides detailed damage effects of a blast wave at different pressure levels, on everything from people and buildings to trains and heavy equipment. The CCPS Guidelines for Evaluating Process Plant Buildings for External Explosion, Fires, and Toxic Releases [5] provides tables for building types, descriptions, building damage levels, and occupant vulnerabilities as a function of building damage levels. These two references, in combination, can be used to determine overpressure levels of concern.

\section{Application of Modeling Results in PHA Meeting}

Once the modeling has been completed the overpressure impact distance results can be used to develop an easy to use spreadsheet, matrix, or graph. This can be made available to PHA teams in order to determine the overpressure distances associated with a heater explosion. Figure 1 below shows an example of how the information in Section 4.2 can be used to develop an easy to use matrix.

\section{Figure 1 - Simple Consequence Model Matrix Example}




\begin{tabular}{|c|c|c|c|c|c|c|c|}
\hline Feed Rate & & & Example B & $\begin{array}{l}\text { st Overpre } \\
\text { al Gas Fired H }\end{array}$ & $\begin{array}{l}\text { ure Matrix } \\
\text { er }\end{array}$ & & \\
\hline $\begin{array}{c}25 \mathrm{lbs} / \mathrm{min} \\
(\sim 30.93 \mathrm{MMBTU} / \mathrm{HR})\end{array}$ & $\begin{aligned} 1.0 \mathrm{psi} & =40.02 \text { feet } \\
1.5 \mathrm{psi} & =31.87 \mathrm{feet} \\
2.5 \mathrm{psi} & =24.60 \mathrm{feet} \\
3.75 \mathrm{psi} & =20.46 \text { feet }\end{aligned}$ & $\begin{aligned} 1.0 \mathrm{psi} & =48.49 \text { feet } \\
1.5 \mathrm{psi} & =37.31 \text { feet } \\
2.5 \mathrm{psi} & =29.22 \text { feet } \\
3.75 \mathrm{psi} & =24.05 \text { feet }\end{aligned}$ & $\begin{array}{l}1.0 \mathrm{psi}=54.78 \text { feet } \\
1.5 \mathrm{psi}=43.10 \mathrm{feet} \\
2.5 \mathrm{psi}=32.66 \mathrm{feet} \\
3.75 \mathrm{psi}=26.73 \text { feet }\end{array}$ & $\begin{array}{l}1.0 \mathrm{psi}=67.46 \text { feet } \\
1.5 \mathrm{psi}=52.74 \text { feet } \\
2.5 \mathrm{psi}=38.59 \text { feet } \\
3.75 \mathrm{psi}=31.12 \text { feet }\end{array}$ & $\begin{array}{l}1.0 \mathrm{psi}=78.78 \text { feet } \\
1.5 \mathrm{psi}=61.35 \text { feet } \\
2.5 \mathrm{psi}=45.78 \text { feet } \\
3.75 \mathrm{psi}=36.93 \text { feet }\end{array}$ & $\begin{aligned} 1.0 \mathrm{psi} & =88.31 \text { feet } \\
1.5 \mathrm{psi} & =67.36 \text { feet } \\
2.5 \mathrm{psi} & =49.54 \text { feet } \\
3.75 \mathrm{psi} & =39.40 \text { feet }\end{aligned}$ & $\begin{array}{r}1.0 \mathrm{psi}=96.70 \text { feet } \\
1.5 \mathrm{psi}=73.74 \text { feet } \\
2.5 \mathrm{psi}=54.12 \text { feet } \\
3.75 \mathrm{psi}=42.97 \text { feet }\end{array}$ \\
\hline $\begin{array}{c}20 \mathrm{lbs} / \mathrm{min} \\
(\sim 24.74 \mathrm{MMBTU} / \mathrm{HR})\end{array}$ & $\begin{aligned} 1.0 \mathrm{psi} & =39.02 \text { feet } \\
1.5 \mathrm{psi} & =30.87 \text { feet } \\
2.5 \mathrm{psi} & =23.60 \mathrm{feet} \\
3.75 \mathrm{psi} & =19.46 \text { feet }\end{aligned}$ & $\begin{aligned} 1.0 \mathrm{psi} & =47.49 \text { feet } \\
1.5 \mathrm{psi} & =36.31 \text { feet } \\
2.5 \mathrm{psi} & =28.22 \text { feet } \\
3.75 \mathrm{psi} & =23.05 \text { feet }\end{aligned}$ & $\begin{array}{l}1.0 \mathrm{psi}=53.78 \text { feet } \\
1.5 \mathrm{psi}=42.10 \mathrm{feet} \\
2.5 \mathrm{psi}=31.66 \text { feet } \\
3.75 \mathrm{psi}=25.73 \text { feet }\end{array}$ & $\begin{array}{c}1.0 \mathrm{psi}=66.46 \text { feet } \\
1.5 \mathrm{psi}=51.74 \text { feet } \\
2.5 \mathrm{psi}=37.59 \text { feet } \\
3.75 \mathrm{psi}=30.12 \text { feet }\end{array}$ & $\begin{array}{l}1.0 \mathrm{psi}=77.78 \text { feet } \\
1.5 \mathrm{psi}=60.35 \text { feet } \\
2.5 \mathrm{psi}=44.78 \text { feet } \\
3.75 \mathrm{psi}=35.93 \text { feet }\end{array}$ & $\begin{aligned} 1.0 \mathrm{ps} i & =87.31 \text { feet } \\
1.5 \mathrm{psi} & =66.36 \text { feet } \\
2.5 \mathrm{psi} & =48.54 \text { feet } \\
3.75 \mathrm{psi} & =38.40 \text { feet }\end{aligned}$ & $\begin{array}{l}1.0 \mathrm{psi}=95.70 \text { feet } \\
1.5 \mathrm{psi}=72.74 \text { feet } \\
2.5 \mathrm{psi}=53.12 \text { feet } \\
3.75 \mathrm{psi}=41.97 \text { feet }\end{array}$ \\
\hline $\begin{array}{c}15 \mathrm{lbs} / \mathrm{min} \\
(\sim 18.56 \mathrm{MMBTU} / \mathrm{HR})\end{array}$ & $\begin{aligned} 1.0 \mathrm{psi} & =38.02 \mathrm{feet} \\
1.5 \mathrm{psi} & =29.87 \mathrm{feet} \\
2.5 \mathrm{psi} & =22.60 \mathrm{feet} \\
3.75 \mathrm{psi} & =18.46 \mathrm{feet}\end{aligned}$ & $\begin{aligned} 1.0 \mathrm{psi} & =46.49 \text { feet } \\
1.5 \mathrm{psi} & =35.31 \text { feet } \\
2.5 \mathrm{psi} & =27.22 \mathrm{feet} \\
3.75 \mathrm{psi} & =22.05 \text { feet }\end{aligned}$ & $\begin{array}{l}1.0 \mathrm{psi}=52.78 \text { feet } \\
1.5 \mathrm{psi}=41.10 \text { feet } \\
2.5 \mathrm{psi}=30.66 \text { feet } \\
3.75 \mathrm{psi}=24.73 \text { feet }\end{array}$ & $\begin{array}{l}1.0 \mathrm{psi}=65.46 \text { feet } \\
1.5 \mathrm{psi}=50.74 \text { feet } \\
2.5 \mathrm{psi}=36.59 \text { feet } \\
3.75 \mathrm{psi}=29.12 \text { feet }\end{array}$ & $\begin{array}{l}1.0 \mathrm{psi}=76.78 \text { feet } \\
1.5 \mathrm{psi}=59.35 \text { feet } \\
2.5 \mathrm{psi}=43.78 \text { feet } \\
3.75 \mathrm{psi}=34.93 \text { feet }\end{array}$ & $\begin{aligned} 1.0 \mathrm{psi} & =86.31 \text { feet } \\
1.5 \mathrm{psi} & =65.36 \text { feet } \\
2.5 \mathrm{psi} & =47.54 \text { feet } \\
3.75 \mathrm{psi} & =37.40 \mathrm{feet}\end{aligned}$ & $\begin{array}{l}1.0 \mathrm{psi}=94.70 \text { feet } \\
1.5 \mathrm{psi}=71.74 \text { feet } \\
2.5 \mathrm{psi}=52.12 \text { feet } \\
3.75 \mathrm{psi}=40.97 \text { feet }\end{array}$ \\
\hline $\begin{array}{c}10 \mathrm{lbs} / \mathrm{min} \\
(\sim 12.37 \mathrm{MMBTU} / \mathrm{HR})\end{array}$ & $\begin{aligned} 1.0 \mathrm{psi} & =37.02 \text { feet } \\
1.5 \mathrm{psi} & =28.87 \mathrm{feet} \\
2.5 \mathrm{psi} & =21.60 \mathrm{feet} \\
3.75 \mathrm{psi} & =17.46 \mathrm{feet}\end{aligned}$ & $\begin{aligned} 1.0 \mathrm{psi} & =45.49 \text { feet } \\
1.5 \mathrm{psi} & =34.31 \text { feet } \\
2.5 \mathrm{psi} & =26.22 \text { feet } \\
3.75 \mathrm{psi} & =21.05 \text { feet }\end{aligned}$ & $\begin{aligned} 1.0 \mathrm{psi} & =51.78 \text { feet } \\
1.5 \mathrm{psi} & =40.10 \mathrm{feet} \\
2.5 \mathrm{psi} & =29.66 \text { feet } \\
3.75 \mathrm{psi} & =23.73 \text { feet }\end{aligned}$ & $\begin{array}{l}1.0 \mathrm{psi}=64.46 \text { feet } \\
1.5 \mathrm{psi}=49.74 \text { feet } \\
2.5 \mathrm{psi}=35.59 \text { feet } \\
3.75 \mathrm{psi}=28.12 \text { feet }\end{array}$ & $\begin{array}{l}1.0 \mathrm{psi}=75.78 \text { feet } \\
1.5 \mathrm{psi}=58.35 \text { feet } \\
2.5 \mathrm{psi}=42.78 \text { feet } \\
3.75 \mathrm{psi}=33.93 \text { feet }\end{array}$ & $\begin{aligned} 1.0 \mathrm{psi} & =85.31 \text { feet } \\
1.5 \mathrm{psi} & =64.36 \text { feet } \\
2.5 \mathrm{psi} & =46.54 \text { feet } \\
3.75 \mathrm{psi} & =36.40 \text { feet }\end{aligned}$ & $\begin{array}{l}1.0 \mathrm{psi}=93.70 \text { feet } \\
1.5 \mathrm{psi}=70.74 \text { feet } \\
2.5 \mathrm{psi}=51.12 \text { feet } \\
3.75 \mathrm{psi}=39.97 \text { feet }\end{array}$ \\
\hline $\begin{array}{c}5 \mathrm{lbs} / \mathrm{min} \\
(\sim 6.19 \mathrm{MMBTU} / \mathrm{HR})\end{array}$ & $\begin{aligned} 1.0 \mathrm{psi} & =36.02 \mathrm{feet} \\
1.5 \mathrm{psi} & =27.87 \mathrm{feet} \\
2.5 \mathrm{psi} & =20.60 \mathrm{feet} \\
3.75 \mathrm{psi} & =16.46 \mathrm{feet}\end{aligned}$ & $\begin{aligned} 1.0 \mathrm{psi} & =44.49 \text { feet } \\
1.5 \mathrm{psi} & =33.31 \text { feet } \\
2.5 \mathrm{psi} & =25.22 \text { feet } \\
3.75 \mathrm{psi} & =20.05 \text { feet }\end{aligned}$ & $\begin{aligned} 1.0 \mathrm{psi} & =50.78 \text { feet } \\
1.5 \mathrm{psi} & =39.10 \mathrm{feet} \\
2.5 \mathrm{psi} & =28.66 \text { feet } \\
3.75 \mathrm{psi} & =22.73 \text { feet }\end{aligned}$ & $\begin{array}{l}1.0 \mathrm{psi}=63.46 \text { feet } \\
1.5 \mathrm{psi}=48.74 \text { feet } \\
2.5 \mathrm{psi}=34.59 \text { feet } \\
3.75 \mathrm{psi}=28.12 \text { feet }\end{array}$ & $\begin{array}{l}1.0 \mathrm{psi}=74.78 \text { feet } \\
1.5 \mathrm{psi}=57.35 \text { feet } \\
2.5 \mathrm{psi}=41.78 \text { feet } \\
3.75 \mathrm{psi}=32.93 \text { feet }\end{array}$ & $\begin{aligned} 1.0 \mathrm{psi} & =84.31 \text { feet } \\
1.5 \mathrm{psi} & =63.36 \text { feet } \\
2.5 \mathrm{psi} & =45.54 \text { feet } \\
3.75 \mathrm{psi} & =35.40 \text { feet }\end{aligned}$ & $\begin{array}{r}1.0 \mathrm{psi}=91.70 \text { feet } \\
1.5 \mathrm{psi}=69.74 \text { feet } \\
2.5 \mathrm{psi}=50.12 \text { feet } \\
3.75 \mathrm{psi}=38.97 \text { feet }\end{array}$ \\
\hline $\begin{array}{c}2 \mathrm{lbs} / \mathrm{min} \\
(\sim 2.47 \mathrm{MMBTU} / \mathrm{HR})\end{array}$ & $\begin{array}{l}1.0 \mathrm{psi}=35.02 \text { feet } \\
1.5 \mathrm{psi}=26.87 \mathrm{feet} \\
2.5 \mathrm{psi}=19.60 \mathrm{feet} \\
3.75 \mathrm{psi}=15.46 \text { feet }\end{array}$ & $\begin{aligned} 1.0 \mathrm{psi} & =43.49 \text { feet } \\
1.5 \mathrm{psi} & =33.31 \text { feet } \\
2.5 \mathrm{psi} & =24.22 \text { feet } \\
3.75 \mathrm{psi} & =19.05 \text { feet }\end{aligned}$ & $\begin{array}{l}1.0 \mathrm{psi}=49.78 \mathrm{feet} \\
1.5 \mathrm{psi}=38.10 \mathrm{feet} \\
2.5 \mathrm{psi}=27.66 \text { feet } \\
3.75 \mathrm{psi}=21.73 \text { feet }\end{array}$ & $\begin{array}{l}1.0 \mathrm{psi}=62.46 \text { feet } \\
1.5 \mathrm{psi}=47.74 \text { feet } \\
2.5 \mathrm{psi}=34.59 \text { feet } \\
3.75 \mathrm{psi}=27.12 \text { feet }\end{array}$ & $\begin{array}{l}1.0 \mathrm{psi}=73.78 \text { feet } \\
1.5 \mathrm{psi}=56.35 \text { feet } \\
2.5 \mathrm{psi}=40.78 \text { feet } \\
3.75 \mathrm{psi}=31.93 \text { feet }\end{array}$ & $\begin{array}{l}1.0 \mathrm{psi}=83.30 \text { feet } \\
1.5 \mathrm{psi}=63.35 \text { feet } \\
2.5 \mathrm{psi}=45.53 \text { feet } \\
3.75 \mathrm{psi}=35.40 \text { feet }\end{array}$ & $\begin{array}{l}1.0 \mathrm{psi}=91.37 \text { feet } \\
1.5 \mathrm{psi}=69.49 \text { feet } \\
2.5 \mathrm{psi}=49.95 \text { feet } \\
3.75 \mathrm{psi}=38.83 \text { feet }\end{array}$ \\
\hline $\begin{array}{c}1 \mathrm{lbs} / \mathrm{min} \\
(\sim 1.24 \mathrm{MMBTU} / \mathrm{HR})\end{array}$ & $\begin{array}{l}1.0 \mathrm{psi}=34.02 \text { feet } \\
1.5 \mathrm{psi}=25.87 \mathrm{feet} \\
2.5 \mathrm{psi}=18.60 \mathrm{feet} \\
3.75 \mathrm{psi}=14.46 \mathrm{feet}\end{array}$ & $\begin{array}{l}1.0 \mathrm{psi}=42.49 \text { feet } \\
1.5 \mathrm{psi}=32.31 \text { feet } \\
2.5 \mathrm{psi}=23.22 \text { feet } \\
3.75 \mathrm{psi}=18.05 \text { feet }\end{array}$ & $\begin{array}{l}1.0 \mathrm{psi}=48.78 \text { feet } \\
1.5 \mathrm{psi}=37.10 \mathrm{feet} \\
2.5 \mathrm{psi}=26.66 \text { feet } \\
3.75 \mathrm{psi}=20.73 \text { feet }\end{array}$ & $\begin{array}{l}1.0 \mathrm{psi}=61.46 \text { feet } \\
1.5 \mathrm{psi}=46.74 \text { feet } \\
2.5 \mathrm{psi}=33.59 \text { feet } \\
3.75 \mathrm{psi}=26.12 \mathrm{feet}\end{array}$ & $\begin{array}{l}1.0 \mathrm{psi}=72.59 \text { feet } \\
1.5 \mathrm{psi}=55.20 \text { feet } \\
2.5 \mathrm{psi}=39.68 \text { feet } \\
3.75 \mathrm{psi}=30.85 \text { feet }\end{array}$ & $\begin{array}{l}1.0 \mathrm{psi}=81.57 \text { feet } \\
1.5 \mathrm{psi}=62.04 \text { feet } \\
2.5 \mathrm{psi}=44.59 \text { feet } \\
3.75 \mathrm{psi}=34.67 \mathrm{feet}\end{array}$ & $\begin{array}{l}1.0 \mathrm{psi}=86.90 \text { feet } \\
1.5 \mathrm{psi}=66.09 \text { feet } \\
2.5 \mathrm{psi}=47.50 \text { feet } \\
3.75 \mathrm{psi}=36.93 \text { feet }\end{array}$ \\
\hline Firebox Volume & $50 \mathrm{ft}^{\wedge} 3$ & $100 \mathrm{ft}^{\wedge} 3$ & $150 \mathrm{ft}^{\wedge} 3$ & $300 \mathrm{ft}^{\wedge} 3$ & $500 \mathrm{ft}^{\wedge} 3$ & $750 \mathrm{ft}^{\wedge} 3$ & $1000 \mathrm{ft}^{\wedge} 3$ \\
\hline
\end{tabular}

The above matrix was configured using fuel feed rates/heating capacities and firebox volumes. It is based on fuel type, and therefore this matrix is only applicable for natural gas fired heaters. Therefore, the matrix can be used to determine the overpressure distance at specified overpressure levels of concern for different heater combinations using the feed rates/heating capacities and firebox volumes.

The modeling results can also be used to developed overpressure distance graphs. Graphing the results provides additional details on pressure rise rate for a specified fuel feed rate/heating capacity relative to firebox volume. They are most beneficial when used along with a spreadsheet or matrix because if a heater's fuel feed rate/heating capacity or firebox volume falls between the ranges on a spreadsheet or matrix, the graph can be used to derive the overpressure distance. Figure 2 below shows an example of how the information in Sections 4.2 can be used to develop a graph.

Figure 2 - Simple Consequence Model Graph Example 


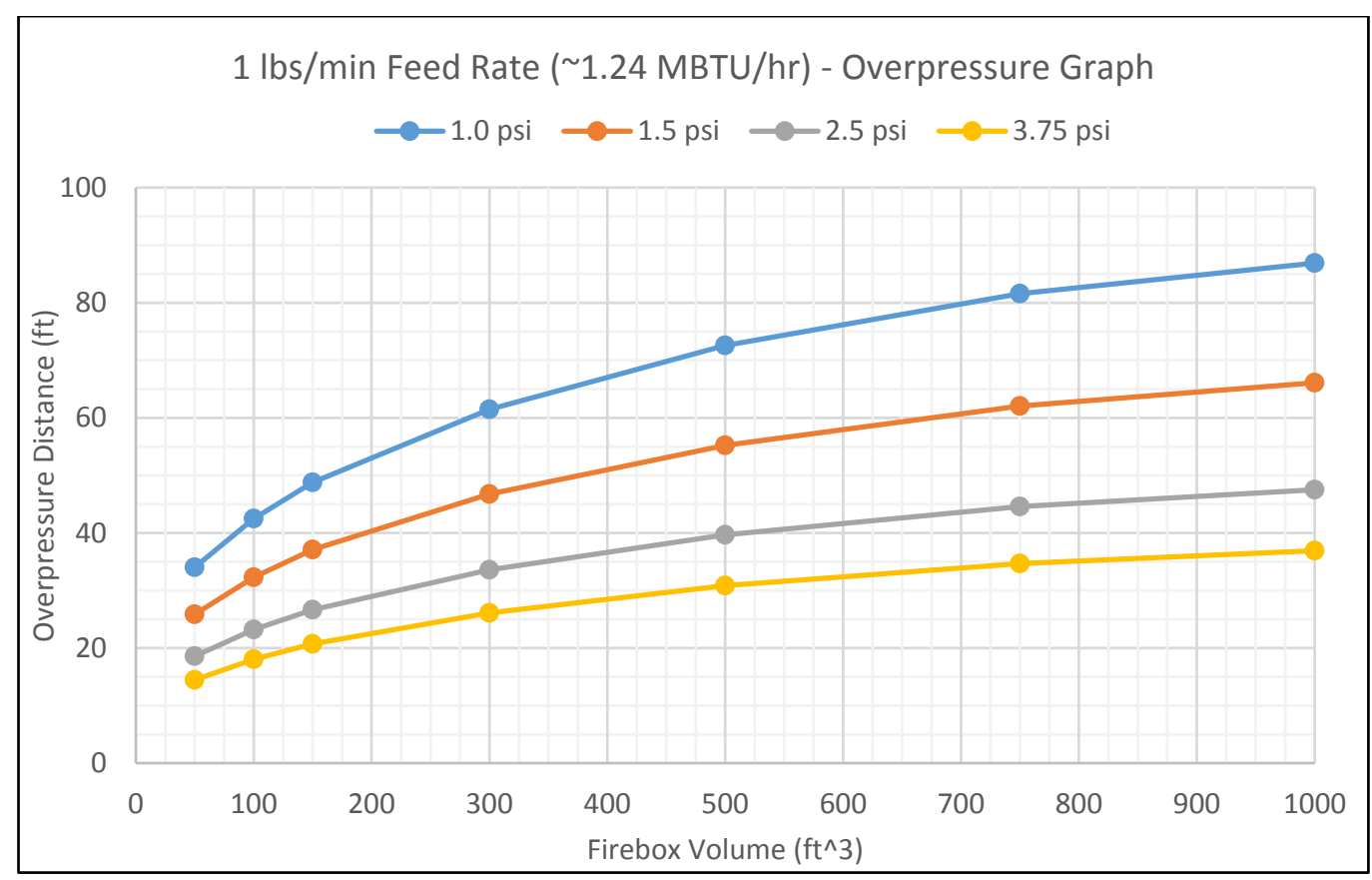

Having the overpressure distances is a tremendous asset when trying to determine the overpressure impacts of a heater explosion scenario. However, the overpressure distances alone do not provide a PHA team with all the information needed to determine the impacts to personnel or buildings located within the overpressure levels. Therefore, quick reference tables should be developed using the information provided in Lees' Loss Prevention in the Process Industries: Hazard Identification, Assessment and Control [4] and CCPS Guidelines for Evaluating Process Plant Buildings for External Explosion, Fires, and Toxic Releases [5] so that the overpressure distances can be translated into building damage levels and occupant vulnerability, and potential for personnel injury/fatality. Figures 3 and 4 below show tables developed using these references. 


\section{Figure 3 - Explosion Overpressure Damage Table Example}

\begin{tabular}{|c|c|}
\hline $\begin{array}{l}\text { Peak } \\
\text { overpressure } \\
\text { (psig) }\end{array}$ & Level of Damage Expected \\
\hline 0.02 & Annoying noise $(137 \mathrm{~dB})$, if of low frequency $(1-15 \mathrm{~Hz})$ \\
\hline 0.03 & Occasional breaking of large glass windows already under strain \\
\hline 0.04 & Loud noise (143 dB); Sonic boom glass failure \\
\hline 0.10 & Breaking of small windows under strain \\
\hline 0.15 & Typical pressure for glass breaking \\
\hline 0.30 & $\begin{array}{l}\text { "Safe distance" (probability } 0.95 \text { no serious damage beyond this value) } \\
\text { Missile limit } \\
\text { Some damage to house ceilings; } 10 \% \text { window glass broken }\end{array}$ \\
\hline 0.40 & Limited minor structural damage \\
\hline $0.50-1.0$ & Large and small windows usually shattered; occasional damage to window frames \\
\hline 0.70 & Minor damage to house structures \\
\hline 1.0 & Partial demolition of houses, made uninhabitable \\
\hline $1.0-2.0$ & $\begin{array}{l}\text { Corrugated asbestos shattered } \\
\text { Corrugated steel or aluminum panels, fastenings fail, followed by buckling } \\
\text { Wood panels (standard housing) fastenings fail, panels blown in }\end{array}$ \\
\hline 1.3 & Steel frame of clad building slightly distorted \\
\hline 2.0 & Partial collapse of walls and roofs of houses \\
\hline $2.0-3.0$ & Concrete or cinder block walks, not reinforced, shattered \\
\hline 2.3 & Lower limit of serious structural damage \\
\hline $2.4-12.2$ & Range for $1-90 \%$ eardrum rupture among exposed populations \\
\hline 2.5 & $50 \%$ destruction of brickwork of houses \\
\hline 3.0 & Steel frame building distorted and pulled away from foundation \\
\hline $3.0-4.0$ & Frameless steel panel building ruined \\
\hline 4.0 & Cladding of light industrial buildings ruptured \\
\hline 5.0 & Wooded utility poles snapped \\
\hline $5.0-7.0$ & Nearly complete destruction of houses \\
\hline 7.0 & Loaded train wagons overturned \\
\hline $7.0-8.0$ & Brick panels, $8-12$ in. thick, non-reinforced, fail by shearing of flexure \\
\hline 9.0 & Loaded train boxcars demolished \\
\hline 10.0 & Portable total building destruction \\
\hline $15.5-29.0$ & Range for $1-99 \%$ fatalities among exposed populations due to direct blast effects \\
\hline
\end{tabular}


Figure 4 - Building Vulnerability to Blast Loads Table Example

\begin{tabular}{|c|c|c|c|}
\hline Pressure (psig) & Building Type & Damage Level & Vulnerability to Occupants \\
\hline 1.5 & \multirow{3}{*}{$\begin{array}{l}\text { Steel Framed Building with Metal Panel Roof } \\
\text { and Walls } \\
\text { OR } \\
\text { Pre-engineered building (metal frame/cladding) }\end{array}$} & Moderate & $1.7 \%$ \\
\hline 2.5 & & Major & $17 \%$ \\
\hline 3.75 & & Collapse & $49 \%$ \\
\hline 1.8 & \multirow{3}{*}{$\begin{array}{l}\text { Trailers/Modular buildings (wood frame and } \\
\text { wall/roof in steel or aluminium cladding) }\end{array}$} & Moderate & $2.5 \%$ \\
\hline 2.0 & & Major & $25 \%$ \\
\hline 3.0 & & Collapse & $77 \%$ \\
\hline
\end{tabular}

Simple consequence modeling is performed using conservative inputs, thus producing conservative results. The impact area results for a fired heater explosion are consequently larger when using the simple consequence modeling approach versus traditional consequence modeling. Therefore, a more detailed analysis should not be required if the simple consequence modeling results show that a heater explosion does not come in contact with an area of concern, or, if it does, that the impacts are within a company's acceptable limits.

Using the overpressure distance results from the simple consequence modeling (Figure 1) in conjunction with the explosion overpressure damage table (Figure 3), building vulnerability table (Figure 4), and a facility plot plan, a PHA team will have the means to efficiently and consistently determine the consequence severity of a heater explosion scenario accurately, using justifiable information, and regardless of team composition. Thereby also reducing the need to make recommendations requiring a more detailed analysis to be performed outside of the meeting in order to confirm the team's initial estimates, and potentially needing to reconvene a team at a later date in order to update a scenario.

\section{Other Applications of Simple Consequence Modeling}

The method above was developed to provide consistency to consequence severity determination for heater explosion scenarios. However, due to the conservative nature of this method, the results can also be considered for use to:

- Evaluate multiple fired heaters at multiple facilities, existing heaters, modifications to existing heaters, and new heaters still in the design stages (as long as the fuel type remains consistent with the model).

- Evaluate EPA RMP applicability (i.e. distance to 1.0 psi overpressure).

- Screen new heaters still in the design phase to evaluate the SIL selected for a fired heater's BMS.

- Locate any new permanent and normally occupied buildings prior to construction, and locating of portable buildings (often used to support Turnaround activates).

- Evaluate the potential impacts to facility siting studies caused by new, relocated, or significantly modified heaters prior to installation. 
- Evaluate emergency evacuation routes, muster locations, emergency response team equipment locations, and first responder facility access points to determine if they are safe/adequate or should be relocated.

\section{Conclusion}

By performing simple consequence modeling prior to a PHA, heater explosion scenarios can be evaluated efficiently and consistently using justifiable information for severity determination. Thereby, eliminating inconsistencies in the consequence severity estimations between analyses caused by varying PHA teams, saving PHA meeting time, and providing defensible results. Simple consequence models can be applied to a range of heaters by using conservative simplifications of in-field equipment specifications and process conditions. As process safety in our industry continues to evolve and facilities continue to narrow down their process risks, consistency in severity determination becomes ever more important to help continue narrowing down risk, while making processes safer cost effectively.

\section{Disclaimer}

Although it is believed that the information in this paper is factual, no warranty or representation, expressed or implied, is made with respect to any or all of the content thereof, and no legal responsibility is assumed therefore. The examples and figures shown are simply for illustration, and, as such, do not necessarily represent any company's guidelines. The reader should use data, methodology, formulas, and guidelines that are appropriate for their own particular situation.

\section{References}

[1] Kletz, Trevor. With a foreword by Sir John Harvey-Jones. Trevor Kletz: By Accident... a Life Preventing Them in Industry. PFV Publications, 2000

[2] CCPS. Guidelines for Developing Quantitative Safety Risk Criteria. Center for Chemical Process Safety, American Institute of Chemical Engineers, New York, NY, 2009

[3] CCPS. Guidelines for Consequence Analysis of Chemical Releases. Center for Chemical Process Safety, American Institute of Chemical Engineers, New York, NY, 1999

[4] Lees, F.P. Loss Prevention in the Process Industries: Hazard Identification, Assessment and Control. Butterworth-Heinemann, 3rd Edition, 2005

[5] CCPS. Guidelines for Evaluating Process Plant Buildings for External Explosion, Fires, and Toxic Releases. Center for Chemical Process Safety, American Institute of Chemical Engineers, New York, NY, 2012

[6] EPA. Risk Management Program Chemical Accident Prevention Provisions. Code of Federal Regulations (40 CFR Part 68), 2014

[7] OSHA. Process Safety Management of Highly Hazardous Chemicals. Code of Federal Regulations (29 CFR Part 1910.119), 2013

[8] NFPA. Standard for Ovens and Furnaces. National Fire Protection Association (NFPA 86), Quincy, MA, 2015

[9] Joseph M. Kutcha. An Investigation of Fire and Explosion Accidents in the Chemical, Mining and Fuel-Related Industries - A Manual. Bulletin 680, Bureau of Mines, United States Department of the Interior, 1985 
[10] FEMA. Handbook of Chemical Hazard Analysis Procedures 